\title{
Atrial fibrillation: the cost of illness in Sweden
}

\author{
Lisa Ericson • Lennart Bergfeldt • Ingela Björholt
}

Received: 10 March 2010/Accepted: 15 June 2010/Published online: 1 July 2010

(C) The Author(s) 2010. This article is published with open access at Springerlink.com

\begin{abstract}
Aim To provide an estimate of the annual cost of atrial fibrillation (AF) in Sweden.

Methods Prevalence-based cost analysis of AF in Sweden for 2007. Direct medical (hospitalizations, hospital outpatient care, primary health care, non-pharmacological interventions, pharmaceuticals, and anticoagulation monitoring) and non-medical (transportation associated with health care visits) costs of AF, direct costs of AF complications (stroke and heart failure), and indirect costs (production loss), were included. Data were based on Swedish registries, reports and databases, published literature, and an expert panel.

Results There were 100,557 individuals with AF as primary or secondary diagnosis that were either hospitalized or treated in hospital outpatient care in 2007. The total cost of $\mathrm{AF}$ was estimated at $€ 708$ million. The major cost driver was the direct cost of complications (54\%), followed by hospitalization due to $\mathrm{AF}$ including $\mathrm{AF}$ as secondary diagnosis (18\%), and production loss (12\%).

Conclusion This is a comprehensive, nation-based cost analysis of AF where relevant data were derived from national registries covering the entire Swedish population. The results showed that the annual cost of AF was high in comparison with other diseases, but likely to be
\end{abstract}

\footnotetext{
L. Ericson $(\bowtie) \cdot$ I. Björholt

Nordic Health Economic Research, Sahlgrenska Science Park, Medicinaregatan 8a, 41346 Gothenburg, Sweden

e-mail: le@nheresearch.se

L. Bergfeldt

Department of Molecular and Clinical Medicine/Cardiology,

Sahlgrenska Academy, University of Gothenburg,

Gothenburg, Sweden
}

underestimated as a conservative approach was applied in the analysis.

Keywords Cost of illness - Direct costs - Indirect costs . Atrial fibrillation $\cdot$ Stroke $\cdot$ Heart failure

JEL Classification I10

\section{Introduction}

Atrial fibrillation (AF) is the most common, clinically significant cardiac arrhythmia [1]. The prevalence in the general population is approximately $1 \%$, increasing to nearly $10 \%$ among those over 80 [2]. The number of patients suffering from AF is likely to increase in forthcoming years as the proportion of elderly in the population is rising $[2,3]$ in combination with improved survival associated with concomitant diseases such as coronary heart disease, stroke, and heart failure (HF) [4-8]. Consequently, an increasing demand on resources for patients with AF and its related diseases is to be expected. The rationale for cost-of-illness studies is the contribution to health care planning by providing information on costs for managing patients with a specific disease.

Some studies have been published on the costs of AF [9-13] where the results were based on data from a patient sample subsequently extrapolated to the national level. In contrast, the present study uses mainly nationwide data. Several registries covering the entire Swedish population $(>9$ million people) have been maintained for many years offering unique opportunities for research particularly as the information is based on unique personal identification numbers. For the present study, the availability of observed frequencies of hospitalizations from the Patient Registry at 
the Swedish National Board of Health and Welfare and sick-leave listing from the Swedish Social Insurance Agency were of particular interest. To our knowledge, no previous study on the costs of AF has been based on such a comprehensive approach. The objective of this study was thus to estimate the annual costs of AF in Sweden by utilizing available, population-based data, and by considering the costs of both AF per se and the costs of its main complications stroke and HF.

\section{Methods}

This study is a prevalence-based, cost-of-illness analysis based on the entire Swedish population $(n=9,182,927)$. Both the top-down approach, where national frequencies and events formed the basis for estimates, and the bottomup approach, where costs for a defined subpopulation were estimated and then extrapolated to represent the entire population, was used $[14,15]$.

Information not available in Swedish registries, reports or databases, or in the published literature, was estimated from individual telephone interviews with an expert panel, including three cardiologists and two general practitioners from different parts of Sweden. The questions posed were related to treatment practices, such as hospital outpatient or primary health care and pharmaceuticals.

All costs were estimated in SEK according to 2007 prices and then converted to Euros $(€ 1.00=$ SEK9.25) and, where applicable, the consumer price index (CPI) was applied as the conversion factor.

\section{Diagnosis definitions}

Diagnoses were defined according to the ICD-10 classification system. AF was assessed both as primary and as secondary diagnosis and the code I48 (I48.9), comprising both atrial fibrillation and flutter, was used.

Stroke was defined as either I63 "ischaemic stroke" or I64 "unspecified stroke". HF was defined as I50, which includes the subgroups "congestive heart failure", "left ventricular failure", and "unspecified heart failure".

\section{Direct medical costs of atrial fibrillation}

The direct medical costs of AF included inpatient care (hospitalization), hospital outpatient care (specialist visits), primary health care (general practitioner visits), nonpharmacological interventions (inpatient and outpatient procedures), pharmacological treatment, and anticoagulation monitoring. Data on hospitalization and hospital outpatient care including non-pharmacological interventions, as well as the average number of visits per patient yearly were retrieved from the Patient Registry at the Swedish National Board of Health and Welfare, and was based on 2007. This Registry does, however, not provide any primary health care data. The proportion of AF patients treated in hospital outpatient and primary health care, respectively, was assumed to be $50 \%$ in each setting according to expert panel. That is, the estimated number of primary health care visits applied in the present analysis was equal to the number of hospital outpatient visits retrieved from the Patient Registry.

The cost of AF as a secondary diagnosis was included in the analysis. The number of hospitalizations for patients with $\mathrm{AF}$ as secondary diagnosis was calculated as the number of all hospitalizations with AF (primary and secondary) less the number of hospitalizations with $\mathrm{AF}$ as primary diagnosis. This data were retrieved from the Patient Registry, whereas the disorders and/or cardiovascular risk factors analysed as primary diagnoses, with $\mathrm{AF}$ as secondary diagnosis, were based on findings on what were the most common concomitant diseases/risk factors according to the Euro Heart Survey on Atrial Fibrillation [16]. These diagnoses include hypertensive diseases, ischaemic heart diseases, valvular heart diseases, diabetes mellitus, and hyperlipidaemia. The occurrence of hospitalizations with AF listed as secondary diagnosis is thus based on actual and on observed data, while the primary diagnoses were assumed to reflect a common disease profile of AF patients as evidenced in the literature. A detailed analysis of these diagnoses was beyond the scope of the present study. Stroke and HF were analysed separately.

The costs of hospitalization and interventions were calculated according to the Diagnosed Related Groups (DRG) classification system. Costs for DRG weights were obtained from the 2007 inpatient/outpatient list for the Västra Götaland Region (the greater south-western/western area corresponding to $17 \%$ of the total Swedish population). Costs of specialist or general practitioner visits were obtained from a medical price list ("Utomlänsprislista") from 2007 for the same region.

The percentage use of rate (digoxin, beta-blockers, verapamil/diltiazem) and rhythm (sotalol, flecainide/propafenone, disopyramide, amiodarone) control agents was derived from the Auricula Registry, a Swedish national quality registry of AF patients [17], whereas antithrombotic (warfarin, ASA) treatment was based on estimates from three Swedish studies [18-20]. Pharmaceutical prices were taken from Pharmaceutical Specialties in Sweden (FASS) [21]. Annual costs were calculated based on an estimated prevalence of 140,000 AF patients (see below).

Concerning anticoagulation monitoring, an annual frequency of 16.18 international normalized ratio (INR) analyses per patient in primary health care was applied from a previous study [22]. It was assumed that the same 
number of INR analyses was monitored at specialized anticoagulation hospital clinics where 58\% [18] of followup was estimated to take place. The cost of monitoring at anticoagulation clinics was obtained from the 2007 price list for the Västra Götaland Region, whereas the cost in primary health care was obtained from the literature [22]. Calculations were again based on an estimated prevalence of 140,000 AF patients. This prevalence was, in turn, based on data from the Patient Registry and estimates of the AF population in primary health care by the expert panel (see "Discussion").

Direct non-medical costs of atrial fibrillation

The only direct non-medical cost included was transportation associated with hospital and primary health care centre visits. The cost for transportation to and from Swedish hospitals was obtained from a previous study [23]. Transportation costs related to hospitalizations were assumed to be twice that of a hospital outpatient visit. The rationale being the health state of such patients normally requires transportation by taxi or the assistance of a caretaker. Primary health care centres, on the other hand, are generally more accessible and, therefore, transportation costs were calculated as half the cost of a hospital outpatient visit.

\section{Direct costs of complications}

The direct costs of complications of AF included stroke and HF. As AF is a strong single risk factor for stroke, all such events were assumed to be due to AF in patients with a previous diagnosis of this cardiac arrhythmia. According to published literature and national guidelines (based on data from the Swedish National Registry for Stroke Care; Riks-Stroke), $20 \%$ of all strokes are related to AF [24, 25]. The number of hospitalized patients diagnosed with stroke was obtained from the open statistical database at the Swedish National Board of Health and Welfare (available at: http://www.socialstyrelsen.se). The direct cost of stroke was adapted from a previous Swedish study by Ghatnekar et al. [26], reporting on the direct life-time costs of stroke based on the incidence approach. Further research from the same group showed that first-ever stroke accounts for $73 \%$ of all stroke events [27]. Thus, the annual direct cost of AFrelated stroke in the present study was calculated as $73 \%$ of the $20 \%$ of the patient population diagnosed with stroke multiplied by the reported life-time direct costs of stroke per patient $(€ 61,910)$. This procedure is in accordance with the method used for estimating annual costs by Ghatnekar et al. [26].

The number of patients diagnosed with HF was calculated from a prevalence of $2 \%$ [28-30] of the Swedish population. Additionally, we estimated that $22 \%$ of patients with HF had a previous diagnosis of AF that played a significant causal role. This estimation was calculated from two publications reporting a causal factor of 20 and $24 \%$, respectively [31, 32]. The direct cost of HF was estimated according to data from a study by Agvall et al. [33], where the annual cost per patient was assessed to $€ 4,358$.

\section{Indirect costs}

Indirect costs included production loss due to (1) sick leave for longer periods than 14 days as those are the only being centrally registered, (2) hospitalizations for AF and its main complications stroke and HF, and (3) hospital outpatient and primary health care visits related to AF per se. These costs were applied to patients $<65$ years of age, the usual Swedish retirement age.

The cost of production loss was estimated from an average salary of $€ 161.62$ per day in the Swedish population, including employer contributions. The number of patients on sick leave for 2007, including the average absence, was retrieved from the Swedish Social Insurance Agency. Absence from work when hospitalized was calculated from the average number of hospitalization days (from the open statistical database at the Swedish National Board of Health and Welfare). A visit to a hospital outpatient clinic or primary health care centre, including transportation, was estimated at two hours.

\section{Data analysis}

Data from national registries are presented descriptively with mean and standard deviation (SD) calculated for relevant variables. For some variables, point estimates were applied from public reports, databases, published literature, or an expert panel. Results are presented in a disaggregated manner to facilitate comparison with other data sources.

\section{Results}

Patient population

A total number of 100,557 individuals had AF as a primary $(\geq 1 / 3$ ) or secondary diagnosis at hospitalization or hospital outpatient care. This number corresponds to a prevalence of $1.1 \%$ of the Swedish population. The mean (SD) age was 74.9 (12.1) years, 78.1 (10.8) years for women, and 72.3 (12.3) years for men. Among these individuals, there were $81,364(81 \%)$ in the age $\geq 65$ years and $44 \%$ were women.

Figure 1 shows the proportion of women and men among patients with AF as the primary or secondary diagnosis and hospitalized or treated in hospital outpatient 
Fig. 1 Proportion of women and men in patients with atrial fibrillation $(n=100,557)$, by age subgroups

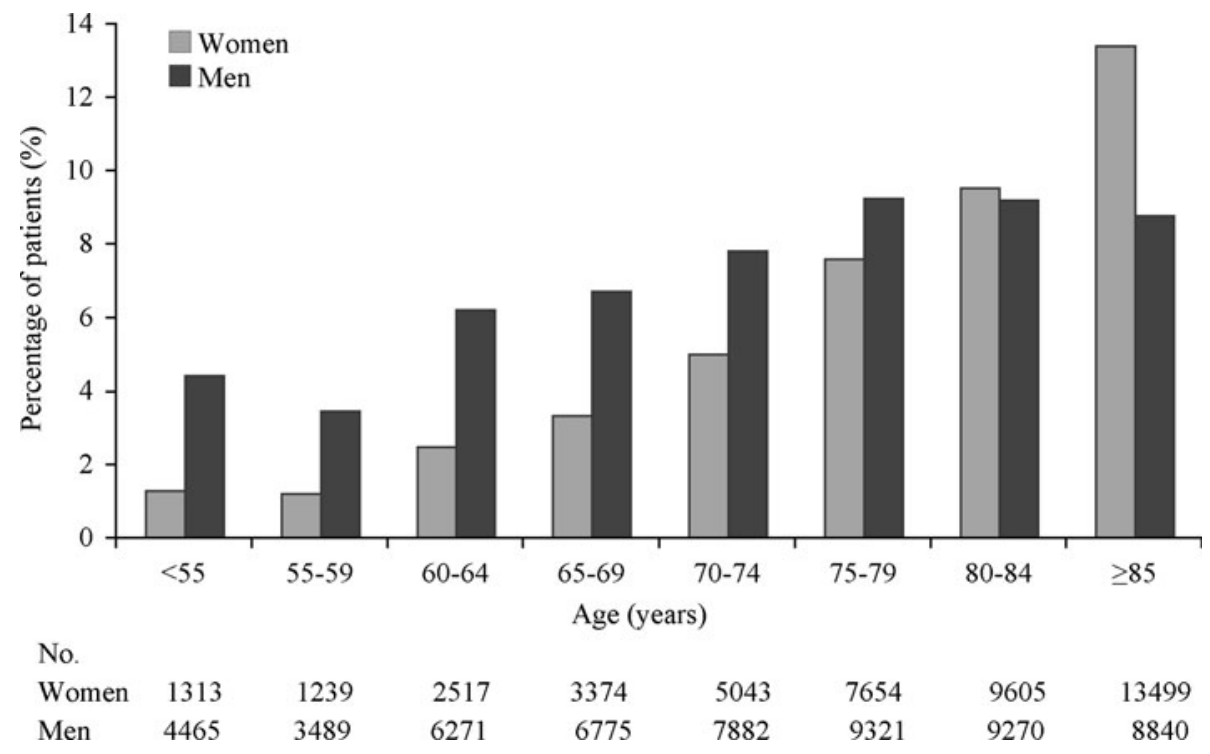

Fig. 2 Proportion of women and men in patients with atrial fibrillation, as a percentage of the Swedish population for each age interval

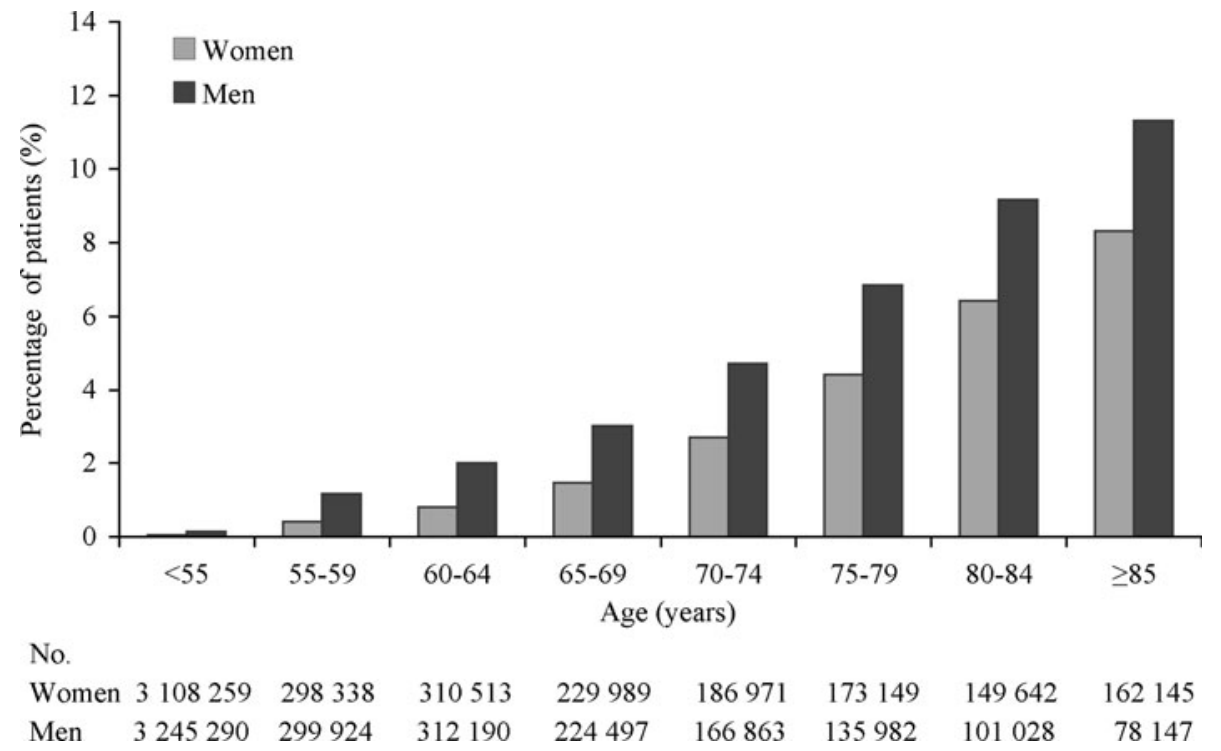

care ( $n=100,557)$, by age subgroup. Figure 2 shows the proportion of women and men with $\mathrm{AF}$ as the primary or secondary diagnosis as a percentage of the entire Swedish population for each age interval.

There were 123,192 hospitalizations, 105,210 (85\%) among patients aged $\geq 65$ years. Twenty-six percent $(32,569)$ of the hospitalizations had a primary diagnosis of AF. The total number of hospital outpatient visits was 80,855 , of those $55,828(69 \%)$ were among patients $\geq 65$ years of age. Sixty-seven percent $(54,218)$ of the hospital outpatient visits were made by patients with a primary AF diagnosis.

The mean (SD) number of hospitalizations per individual with AF as primary diagnosis was 1.49 (1.22) among those aged $<65$ and $1.32(0.83)$ among those aged $\geq 65$.
The corresponding number of hospital outpatient visits was 1.78 (2.06) and 1.54 (1.61), respectively.

\section{Direct costs of atrial fibrillation}

The annual direct costs of AF are shown in Table 1 including details of the type of hospitalization and hospital outpatient visit from the Patient Registry. Table 1 also shows the estimates for primary health care, AF as secondary diagnosis, pharmaceuticals, anticoagulation monitoring, and transportation.

The number of hospitalizations for patients diagnosed with AF as secondary diagnosis was 90,623. A primary diagnosis of myocardial infarction, other ischaemic heart disease, valve disorders, or diabetes mellitus result in an 
Table 1 The annual direct medical and non-medical costs of atrial fibrillation (AF) in Sweden

\begin{tabular}{|c|c|c|c|c|}
\hline Resources & Unit cost $(€)$ & Annual no. & Annual cost $(€$ million $)$ & Sources \\
\hline \multicolumn{5}{|l|}{ Direct medical costs } \\
\hline \multicolumn{2}{|l|}{ Hospitalization (inpatient care) } & & \multicolumn{2}{|l|}{62.00} \\
\hline Electrical cardioversion & 1,233 & 8,600 & 10.60 & [a] \\
\hline Hospitalization, unspecified & 1,233 & 22,560 & 27.82 & [a] \\
\hline Catheter ablation & 11,485 & 857 & 9.84 & [a] \\
\hline His-ablation incl pacemaker & 9,488 & 222 & 2.11 & [a] \\
\hline Maze surgery & 35,234 & 77 & 2.71 & [a] \\
\hline Other surgery for AF & 35,234 & 253 & 8.91 & [a] \\
\hline \multicolumn{3}{|l|}{ Hospital outpatient care } & \multicolumn{2}{|l|}{21.51} \\
\hline Visit to a specialist & 328 & 47,324 & 15.54 & {$[\mathrm{~b}]$} \\
\hline Electrical cardioversion & 824 & 6,811 & 5.61 & [a] \\
\hline Pacemaker or defibrillator $^{\mathrm{c}}$ & 4,267 & 83 & 0.35 & [a] \\
\hline Visit to a general practitioner & 118 & 54,218 & 6.39 & [d] \\
\hline $\mathrm{AF}$ as secondary diagnosis & 685 & 90,623 & 62.05 & [a] \\
\hline Pharmaceuticals & n.a. & n.a. & 19.27 & [e] \\
\hline Anticoagulation monitoring & $23 / 62$ & $1,047,801$ & 41.09 & {$[\mathrm{f}]$} \\
\hline \multicolumn{5}{|l|}{ Direct non-medical costs } \\
\hline Transportation & $14.5 / 29 / 58$ & $1,188,806$ & 28.01 & {$[\mathrm{~g}]$} \\
\hline Total direct cost of $\mathrm{AF}^{\mathrm{h}}$ & \multicolumn{4}{|c|}{240.31} \\
\hline \multirow{2}{*}{\multicolumn{5}{|c|}{$\begin{array}{l}\text { a Unit costs from DRG (Diagnosed Related Groups). Annual no. from the Patient Registry at the Swedish National Board of Health and Welfare } \\
\text { b Unit cost from a medical price list ("Utomlänsprislista") for the Västra Götaland Region. Annual no. from the Patient Registry at the Swedish } \\
\text { National Board of Health and Welfare }\end{array}$}} \\
\hline & & & & \\
\hline \multicolumn{5}{|c|}{ c Insertion, change or removal of pacemaker or defibrillator, short therapy (hospital outpatient procedure) } \\
\hline \multicolumn{5}{|c|}{ d Unit cost from a medical price list ("Utomlänsprislista”) for the Västra Götaland Region. Annual no. estimated by an expert panel } \\
\hline \multicolumn{5}{|c|}{ e Unit costs from reference [21]. Annual no. based on references [17-20] } \\
\hline \multicolumn{5}{|c|}{$\begin{array}{l}\text { f Unit costs (anticoagulation clinic/primary health care) from a medical price list ("Utomlänsprislista") for the Västra Götaland Region, and } \\
\text { reference [22]. Annual no. based on references [18-20, 22] }\end{array}$} \\
\hline \multicolumn{5}{|c|}{$\begin{array}{l}\text { Init costs (primary health care/hospital outpatient care/hospitalization) based on reference [23]. Annual no. from the Patient Registry, } \\
\text { estimates from an expert panel, and references }[18-20,22]\end{array}$} \\
\hline
\end{tabular}

extra DRG cost ranging from $€ 206$ to $€ 2,230$ when accompanied by a secondary diagnosis of AF. Some disorders such as hypertension, angina pectoris, hyperlipidaemia, on the other hand, do not result in higher costs with AF as secondary diagnosis. Taking all those diagnoses into account, the average extra cost of having AF as secondary diagnosis when hospitalized for a different reason was estimated at $€ 685$. Applying this assumption, the resulting cost for all 90,623 hospitalizations was €62.05 million annually.

The annual cost of pharmaceuticals was $€ 19.27$ million, including rate control agents $€ 9.41$ million, rhythm control agents $€ 3.16$ million, and antithrombotic treatment with warfarin $€ 5.52$ million and ASA $€ 1.19$ million.

The annual direct medical and non-medical costs of AF, excluding its complications, were estimated at $€ 212.30$ million and $€ 28.01$ million, respectively.
Direct costs of complications

The annual cost of stroke and HF in patients with a previous diagnosis of AF was based on data from the published literature (see "Methods"). The annual cost of stroke was estimated at $€ 208.64$ million and $\mathrm{HF}$ at $€ 176.07$ million.

\section{Indirect costs}

Table 2 shows the indirect costs of production loss due to $\mathrm{AF}$ and its main complications stroke and HF. During 2007, 1,093 cases of sick leave due to AF, with an average duration of 230 days, were reported in Sweden. Stroke I63 resulted in 1,625 cases with an average of 403 days (365 days applied in the analysis), whereas there were 246 cases for stroke I64 with an average of 353 days. There 
Table 2 The annual indirect costs of production loss of atrial fibrillation and its main complications stroke and heart failure in Swedish patients younger than 65

\begin{tabular}{|c|c|c|c|}
\hline Resources & Annual no. & Annual cost $(€ \text { million })^{\mathrm{a}}$ & Sources \\
\hline Sick leave & & 69.54 & \\
\hline Atrial fibrillation & $251,171^{\mathrm{b}}$ & 40.59 & {$[\mathrm{c}]$} \\
\hline Complications (stroke and heart failure) & $179,094^{\mathrm{b}}$ & 28.95 & {$[\mathrm{~d}]$} \\
\hline Hospitalization & & 4.10 & \\
\hline Atrial fibrillation & $14,953^{\mathrm{b}}$ & 2.42 & {$[\mathrm{e}]$} \\
\hline Complications (stroke and heart failure) & $10,425^{\mathrm{b}}$ & 1.68 & [e] \\
\hline Hospital outpatient and primary health care visits & 238,666 & 9.65 & {$[\mathrm{f}]$} \\
\hline Total indirect cost & & 83.29 & \\
\hline
\end{tabular}

${ }^{a}$ All costs of production loss were estimated from an average Swedish salary (€161.62 per day)

${ }^{b}$ No. of days

c Annual no. from the Swedish Social Insurance Agency

d Annual no. from the Swedish Social Insurance Agency, with adaptations from references [24-32]

e Annual no. from the open statistical database at the Swedish National Board of Health and Welfare

f Annual no. from the Patient Registry at the Swedish National Board of Health and Welfare, estimates from an expert panel, and references [1820, 22]. Two hours per visit; complications not included (not available)

were 685 cases due to $\mathrm{HF}$, with an average of 286 days. The annual cost of sick leave due to AF, including stroke and $\mathrm{HF}$, was estimated at $€ 69.54$ million.

Production loss during hospitalization resulted in an annual cost of $€ 4.10$ million for all three diagnoses. In addition, the annual cost of production loss during visits to a specialist or general practitioner and to anticoagulation monitoring centres among AF patients of working age was estimated at $€ 9.65$ million.

\section{Total costs}

Table 3 summarizes the estimated total direct medical and non-medical as well as indirect costs of $\mathrm{AF}$ and its main complications stroke and HF. The annual total cost of AF including stroke and HF was $€ 708$ million, where the total direct and indirect costs of AF represent $€ 293$ million and complications $€ 415$ million.

Table 3 The annual total direct and indirect costs of atrial fibrillation and its main complications stroke and heart failure, in Sweden

\begin{tabular}{lc}
\hline Resources & $\begin{array}{l}\text { Annual cost } \\
(€ \text { million })\end{array}$ \\
\hline Direct medical cost of atrial fibrillation & 212.3 \\
Direct non-medical cost of atrial fibrillation & 28.0 \\
Direct cost of complications (stroke and heart & 384.7 \\
$\quad$ failure) & 52.7 \\
Indirect cost of atrial fibrillation & 30.6 \\
Indirect cost of complications (stroke and heart & \\
$\quad$ failure) & 708 \\
Total cost & \\
\hline
\end{tabular}

\section{Discussion}

This is a comprehensive analysis of the annual direct and indirect costs of $\mathrm{AF}$ where relevant data have been derived from national registries covering the entire Swedish population of more than nine million people. The total cost of $\mathrm{AF}$ and its main complications stroke and HF was estimated at $€ 708$ million, corresponding to $€ 77$ per inhabitant. The major cost driver was the direct cost of complications ( $€ 385$ million; $54 \%$ ), followed by hospitalizations due to $\mathrm{AF}$ including $\mathrm{AF}$ as secondary diagnosis ( $€ 124$ million; $18 \%$ ), and production loss ( $€ 83$ million; $12 \%$ ).

As shown in Fig. 1, the prevalence of AF increases with age in accordance with previous data [2]. Among those aged $\geq 80$, the increase was apparent only in women possibly explained by this age group being the most rapidly growing with women tending to live longer than men [3]. As a consequence of the ageing population, AF-related resource costs within health care as well as social services will most likely escalate in the future [2].

The AF prevalence of $1.1 \%$ in the Swedish population, based on the 100,557 individuals identified with AF either as primary or as secondary diagnosis in hospital care, represents the lower limit. There are no reliable figures on the total prevalence of AF available for Sweden to date. It has, however, been documented that approximately onethird of AF patients and more than 50\% of paroxysmal episodes are asymptomatic [34]. Furthermore, there are additional patients with no hospital contact or treatment in primary health care, the number of which can only be assumed. Approximations of up to 150,000 AF patients in Sweden have been proposed [17], but the accuracy of this 
number is uncertain. In this study, we estimated the prevalence of AF in Sweden at approximately 140,000. This estimate was used in the calculations of the costs for pharmaceuticals and anticoagulation monitoring, thus representing a minor part of the total cost.

Based on the total cost of AF of $€ 708$ million, the annual cost per patient in Sweden would be $€ 4,722$ with a prevalence of 150,000 , whereas the corresponding cost for a prevalence of 140,000 would be $€ 5,059$. In a sub-study of the Euro Heart Survey on AF, which included five European countries, the average annual per-patient cost ranged from $€ 1,010$ to $€ 3,225$ [12]. Furthermore, a previous French cost of care survey reported an annual cost per patient of $€ 3,209$ [9] and, in another French cost analysis based on clinical and economic literature, the annual cost of $\mathrm{AF}$ was estimated at $€ 3,308$ per patient [35]. In contrast, two other studies have reported lower annual costs. A German study estimated the annual per-patient cost at $€ 827$ [10], whereas in a study from the United Kingdom the estimated direct cost of health care, including nursing homes, in patients with primary diagnosis of AF was approximately $€ 779$ per patient [13]. However, none of the above-cited studies included all the various resource items and their associated costs considered in the present study. The studies reporting a lower per-patient cost did, for example, not include the cost of stroke [13] and/or HF $[10,13]$. In addition, indirect costs due to production loss were only considered in two of the studies $[9,12]$. However, health care management varies between countries and so does the timing of the studies, thus limiting the transferability across both country borders and periods of time.

The total cost of AF presented herein is considerably higher than shown in a previous cost-of-illness analysis based on a sub-set (just over 400,000 people) of the Swedish population [18]. However, that report included only costs of anticoagulation treatment and of stroke as a complication of AF, and may therefore not be appropriate for a direct cost comparison.

To put the total annual cost of AF ( $€ 708$ million) in a wider perspective, the present data were compared with cost analyses for other diseases in Sweden. In a previous analysis of stroke, the direct and indirect annual costs were estimated at $€ 1,330$ million [26]. Furthermore, the annual direct medical cost of HF was estimated at $€ 541$ to $€ 724$ million [33], whereas the estimated direct and indirect costs of diabetes mellitus was $€ 621$ million [15], depression $€ 378$ million [36], breast cancer $€ 324$ million [37], and osteoporosis $€ 610$ million [38]. As expected, costs vary between diseases, which may reflect true differences in costs, but may also reflect differences in the approach of the analyses and that the data were based on previous years.

The ICD-10 codes for subarachnoid and cerebral haemorrhages (I60 and I61) were not included, which may have resulted in an underestimation of the cost of stroke if induced by AF-motivated anticoagulation therapy. However, haemorrhages only affect a minor part of the AF population and some haemorrhages will be covered under I64, "Unspecified stroke".

AF as primary diagnosis defined the total number of hospitalizations and hospital outpatient visits from the Patient Registry, whereas the specific data on non-pharmacological interventions were based on $\mathrm{AF}$ either as primary or as secondary diagnosis. This may imply an underestimation of the cost of AF regarding both hospitalizations and hospital outpatient care. There were, for example, 90,623 hospitalizations where AF was the secondary diagnosis. It is unknown to what degree $\mathrm{AF}$ was truly the secondary diagnosis or whether it should have been the primary diagnosis, as the extent of which miscoding of diagnosis takes place in Swedish hospitals is unknown. In an attempt to somewhat alleviate this potential underestimation, and also to account for the extra costs associated with $\mathrm{AF}$ when hospitalized for a different reason, an extra cost for all hospitalizations where AF was listed as secondary diagnosis was included. It is unlikely that $\mathrm{AF}$ was added as a secondary diagnosis unless it was considered of clinical importance.

The number of electrical cardioversions may have been underestimated in the present report, since these were registered with the so-called KVA ("Kirurgiska Vårdåtgärder") codes, and there is not as yet full coverage of these codes in the Patient Registry. Some electrical cardioversions were probably, however, also included in "unspecified hospitalizations".

The use of rate as well as rhythm control agents was estimated from the Auricula Registry, which includes a somewhat sicker population, mostly in specialist care. These data may, therefore, not be applicable to an average AF population (expert panel). However, the annual cost of all pharmaceuticals as presented herein, only accounts for about $3 \%$ of the total cost of AF, and therefore has only a minor impact on the result.

The average length of sick leave reported herein may appear quite long for AF patients of working age. It concerns, however, a small fraction of the total number of $\mathrm{AF}$ patients, roughly $6 \%$ of individuals under 65 . Those on long-term sick leave may have a severe symptomatic AF and/or been subjected to or waiting for a non-pharmacological intervention. In Sweden, sick-leave periods shorter than 14 days are covered by employers and are not centrally registered. We captured the long-term sick-leave periods from The Swedish Social Insurance Agency and allocated sick leave to patients for the duration of hospital stay, but any sick leave beyond that was not included due to unavailability of information. The cost of sick leave was therefore underestimated. Neither the costs of early 
retirement nor premature mortality was included, thus representing yet another underestimation of the indirect costs of AF.

In conclusion, we have estimated the total cost of AF in Sweden at $€ 708$ million annually. We have used, to our knowledge, the best available sources of information, but our research implies that the results underestimate the true costs and future research should aim to fill the gaps in the analysis.

Acknowledgments This study was sponsored by sanofi-aventis, Bromma, Sweden. The authors wish to thank Dr. Björn Wall, Department of Clinical Physiology, Sahlgrenska University Hospital/ Sahlgrenska, Gothenburg, Sweden, for valuable advice.

Open Access This article is distributed under the terms of the Creative Commons Attribution Noncommercial License which permits any noncommercial use, distribution, and reproduction in any medium, provided the original author(s) and source are credited.

\section{References}

1. Fuster, V., Rydén, L.E., Cannom, D.S., Crijns, H.J., Curtis, A.B., Ellenbogen, K.A., Halperin, J.L., Le Heuzey, J.Y., Kay, G.N., Lowe, J.E., Olsson, S.B., Prystowsky, E.N., Tamargo, J.L., Wann, S., Smith Jr, S.C., Jacobs, A.K., Adams, C.D., Anderson, J.L., Antman, E.M., Hunt, S.A., Nishimura, R., Ornato, J.P., Page, R.L., Riegel, B., Priori, S.G., Blanc, J.J., Budaj, A., Camm, A.J., Dean, V., Deckers, J.W., Despres, C., Dickstein, K., Lekakis, J., McGregor, K., Metra, M., Morais, J., Osterspey, A., Zamorano, J.L.: ACC/AHA/ESC 2006 guidelines for the management of patients with atrial fibrillation: full text: a report of the American College of Cardiology/American Heart Association Task Force on practice guidelines and the European Society of Cardiology Committee for Practice Guidelines (Writing Committee to Revise the 2001 guidelines for the management of patients with atrial fibrillation) developed in collaboration with the European Heart Rhythm Association and the Heart Rhythm Society. Europace 8, 651-745 (2006)

2. Go, A.S., Hylek, E.M., Phillips, K.A., Chang, Y., Henault, L.E., Selby, J.V., Singer, D.E.: Prevalence of diagnosed atrial fibrillation in adults: national implications for rhythm management and stroke prevention: the Anticoagulation and Risk Factors in Atrial Fibrillation (ATRIA) Study. JAMA 285, 2370-2375 (2001)

3. Butler, R.N.: Population aging and health. BMJ 315, 1082-1084 (1997)

4. MacIntyre, K., Capewell, S., Stewart, S., Chalmers, J.W., Boyd, J., Finlayson, A., Redpath, A., Pell, J.P., McMurray, J.J.: Evidence of improving prognosis in heart failure: trends in case fatality in 66547 patients hospitalized between 1986 and 1995. Circulation 102, 1126-1131 (2000)

5. Peltonen, M., Stegmayr, B., Asplund, K.: Time trends in longterm survival after stroke: the Northern Sweden Multinational Monitoring of Trends and Determinants in Cardiovascular Disease (MONICA) study, 1985-1994. Stroke 29, 1358-1365 (1998)

6. Rosamond, W.D., Chambless, L.E., Folsom, A.R., Cooper, L.S., Conwill, D.E., Clegg, L., Wang, C.H., Heiss, G.: Trends in the incidence of myocardial infarction and in mortality due to coronary heart disease, 1987 to 1994. N. Engl. J. Med. 339, 861867 (1998)

7. Schaufelberger, M., Swedberg, K., Köster, M., Rosén, M., Rosengren, A.: Decreasing one-year mortality and hospitalization rates for heart failure in Sweden; Data from the Swedish Hospital Discharge Registry 1988 to 2000. Eur. Heart J. 25, 300-307 (2004)

8. Stegmayr, B., Asplund, K.: Stroke in Northern Sweden. Scand. J. Public Health Suppl. 61, 60-69 (2003)

9. Le Heuzey, J.Y., Paziaud, O., Piot, O., Said, M.A., Copie, X., Lavergne, T., Guize, L.: Cost of care distribution in atrial fibrillation patients: the COCAF study. Am. Heart J. 147, 121-126 (2004)

10. McBride, D., Mattenklotz, A.M., Willich, S.N., Brüggenjürgen, B.: The costs of care in atrial fibrillation and the effect of treatment modalities in Germany. Value Health 12, 293-301 (2008)

11. Reynolds, M.R., Essebag, V., Zimetbaum, P., Cohen, D.J.: Healthcare resource utilization and costs associated with recurrent episodes of atrial fibrillation: the FRACTAL registry. J. Cardiovasc. Electrophysiol. 18, 628-633 (2007)

12. Ringborg, A., Nieuwlaat, R., Lindgren, P., Jönsson, B., Fidan, D., Maggioni, A.P., Lopez-Sendon, J., Stepinska, J., Cokkinos, D.V., Crijns, H.J.: Costs of atrial fibrillation in five European countries: results from the Euro Heart Survey on atrial fibrillation. Europace 10, 403-411 (2008)

13. Stewart, S., Murphy, N.F., Walker, A., McGuire, A., McMurray, J.J.: Cost of an emerging epidemic: an economic analysis of atrial fibrillation in the UK. Heart 90, 286-292 (2004)

14. Ekman, M.: Economic evidence in stroke: a review. Eur. J. Health Econ. 5, S74-S83 (2004)

15. Henriksson, F., Jönsson, B.: Diabetes: the cost of illness in Sweden. J. Intern. Med. 244, 461-468 (1998)

16. Nieuwlaat, R., Capucci, A., Camm, A.J., Olsson, S.B., Andresen, D., Davies, D.W., Cobbe, S., Breithardt, G., Le Heuzey, J.Y., Prins, M.H., Lévy, S., Crijns, H.J.: Atrial fibrillation management: a prospective survey in ESC member countries: the Euro Heart Survey on Atrial Fibrillation. Eur. Heart J. 26, 2422-2434 (2005)

17. Auricula. The atrial fibrillation and anticoagulation registry. Annual report 2007 (In Swedish) (2007). Available at: http://www.ucr.uu.se/auricula. Accessed March 2009

18. Davidson, T., Levin, L.Å.: Kostnaden för förmaksflimmer i Östergötland. CMT Report 2006:5 (In Swedish) (2006). Available at: http://www.ep.liu.se/ea/cmt/2006/005/. Accessed March 2009

19. Friberg, L., Hammar, N., Rosenqvist, M.: Stroke in paroxysmal atrial fibrillation: report from the Stockholm Cohort of Atrial Fibrillation. Eur. Heart J. 31, 967-975 (2010)

20. Nilsson, G.H., Björholt, I.: Occurrence and quality of anticoagulant treatment of chronic atrial fibrillation in primary health care in Sweden: a retrospective study on electronic patient records. BMC Clin. Pharmacol. 4, 1 (2004)

21. FASS, Pharmaceutical Specialties in Sweden (2009). Available at: http://www.fass.se. Accessed March 2009

22. Björholt, I., Andersson, S., Nilsson, G.H., Krakau, I.: The cost of monitoring warfarin in patients with chronic atrial fibrillation in primary care in Sweden. BMC Fam. Pract. 8, 6 (2007)

23. Björholt, I., Andersson, F.L., Kahan, T., Östergren, J.: The costeffectiveness of ramipril in the treatment of patients at high risk of cardiovascular events: a Swedish sub-study to the HOPE study. J. Intern. Med. 251, 508-517 (2002)

24. Atrial fibrillation Investigators: Risk factors for stroke and efficacy of antithrombotic therapy in atrial fibrillation. Analysis of pooled data from five randomized controlled trials. Arch. Intern. Med. 154, 1449-1457 (1994) 
25. The Swedish National Board of Health and Welfare. [National guidelines]. Nationella riktlinjer för strokesjukvård. Beslutsstöd för prioriteringar (In Swedish) (2009). Available at: http:// www.socialstyrelsen.se. Accessed March 2009

26. Ghatnekar, O., Persson, U., Glader, E.L., Terent, A.: Cost of stroke in Sweden: an incidence estimate. Int. J. Technol. Assess. Health Care 20, 375-380 (2004)

27. Ghatnekar, O., Glader, E.L.: The effect of atrial fibrillation on stroke-related inpatient costs in Sweden: a 3-year analysis of registry incidence data from 2001. Value Health 11, 862-868 (2008)

28. Agvall, B., Dahlström, U.: Patients in primary health care diagnosed and treated as heart failure, with special reference to gender differences. Scand. J. Prim. Health Care 19, 14-19 (2001)

29. Mejhert, M., Persson, H., Edner, M., Kahan, T.: Epidemiology of heart failure in Sweden-a national survey. Eur. J. Heart Failure 3, 97-103 (2001)

30. Medical Products Agency: Diagnostik och behandling av kronisk hjärtsvikt-behandlingsrekommendationer (In Swedish). Information från Läkemedelsverket 17, 7-17 (2006)

31. Miyasaka, Y., Barnes, M.E., Gersh, B.J., Cha, S.S., Bailey, K.R., Abhayaratna, W., Seward, J.B., Iwasaka, T., Tsang, T.S.: Incidence and mortality risk of congestive heart failure in atrial fibrillation patients: a community-based study over two decades. Eur. Heart J. 27, 936-941 (2006)

32. Wang, T.J., Larson, M.G., Levy, D., Vasan, R.S., Leip, E.P., Wolf, P.A., D’Agostino, R.B., Murabito, J.M., Kannel, W.B., Benjamin, E.J.: Temporal relations of atrial fibrillation and congestive heart failure and their joint influence on mortality: the Framingham Heart Study. Circulation 107, 2920-2925 (2003)

33. Agvall, B., Borgquist, L., Foldevi, M., Dahlström, U.: Cost of heart failure in Swedish primary healthcare. Scand. J. Prim. Health Care 23, 227-232 (2005)

34. Rho, R.W., Page, R.L.: Asymptomatic atrial fibrillation. Prog. Cardiovasc. Dis. 48, 79-87 (2005)

35. Moeremans, K., Aliot, E., de Chillou, C., Annemans, L., Le Pen, C., de Jong, P.: Second line pharmacological management of paroxysmal and persistent atrial fibrillation in France: a cost analysis. Value Health 3, 407-416 (2000)

36. Sobocki, P., Lekander, I., Borgström, F., Ström, O., Runeson, B.: The economic burden of depression in Sweden from 1997 to 2005. Eur. Psychiatry 22, 146-152 (2007)

37. Lidgren, M., Wilking, N., Jönsson, B.: Cost of breast cancer in Sweden in 2002. Eur. J. Health Econ. 8, 5-15 (2007)

38. Borgström, F., Sobocki, P., Ström, O., Jönsson, B.: The societal burden of osteoporosis in Sweden. Bone 40, 1602-1609 (2007) 